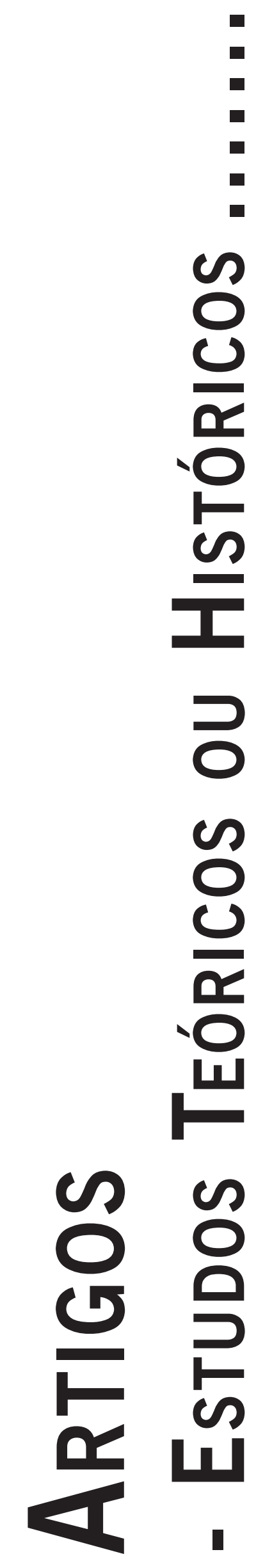




\title{
POR UM ENTENDIMENTO DO QUE SE CHAMA PSICOPATOLOGIA FENOMENOLÓGICA
}

\author{
By an Understanding of what is called Psychopathology Phenomenological
}

Por una Comprensión de lo que se llama Psicopatología Fenomenológica

SiLverio LuCIO KARWOWSKI

\begin{abstract}
Resumo: A fenomenologia em sua interseção com a psicopatologia é examinada por distintos autores em Psicologia e Psiquiatria. Estudiosos de psicopatologia buscam a fenomenologia na tentativa de evitar a nosologia psiquiátrica clássica em suas reduções e rotulações indevidas, bem como para adotar uma teoria humanista, na esperança que essa apresente sistematicamente etiologia, descrição, categorização, prognóstico e terapêutica das doenças mentais. Faz-se necessário o entendimento do que se compreende e se denomina psicopatologia fenomenológica, a fim de se precisar seu alcance, limite, constituição e propósitos. Este trabalho objetiva fazer uma introdução ao estudo do tema, considerando seu contexto de inserção e sua herança. Para tal, fez-se um estudo exploratório mediante exame bibliográfico, reavendo as atuais perspectivas de psicopatologia, mencionando-se as vigentes e hegemônicas e propondo-se uma classificação. Demonstrou-se a vinculação da atual noção de psicopatologia à ideia de doença, constatando-se a não naturalidade da concepção dessa última. Posteriormente, discutiram-se as possibilidades de se intitular a área de estudo em tela como psicopatologia fenomenológica, considerando-se a pertinência e as consequências de sua adoção, fazendo-se, também, uma reflexão sobre possíveis objetivos para o campo de estudo examinado. Concluiu-se que o entendimento da psicopatologia fenomenológica é um campo em evolução, necessitando de delimitações aprofundadas, tanto a partir da prática dos profissionais de saúde como da pertinente reflexão sobre a fenomenologia e a possibilidade de sua adequação à psicopatologia.
\end{abstract}

Palavras-chave: Psicopatologia; Fenomenologia; Psicopatologia fenomenológica.

Abstract: Phenomenology at its intersection with psychopathology is studied by different authors in psychology and psychiatry. Psychopathology Scholars have sought phenomenology in an attempt to avoid classic psychiatric nosology and its unfitting reductionism, as well to adopt a humanist theory, hoping that it systematically presents etiology, description, categorization, prognosis and treatment of mental illness. Therefore, it's necessary the understanding of what is called and known as phenomenological psychopathology, in order to better define its scope, boundary, constitution and purposes. This paper aims to introduce the study of the subject, considering its context insertion and heritage. To that end, it's an exploratory and literature study that rescue the current perspectives of psychopathology, especially the prevailing and hegemonic ones and proposes a classification of them. It is also demonstrated the association between the current notion of psychopathology and the notion of disease, excluding the naturalistic conception of the latter. Thereupon, the possibilities of naming this area of study as phenomenological psychopathology are discussed, considering the relevance and consequences of the naming adoption, making it also a reflection on possible objectives for the field of study examined. It was concluded that the understanding of phenomenological psychopathology is field in construction, relinquishing both depth contours from the practice of health professionals and relevant pensiveness on the phenomenology, as well as the possibility of its adaptation to the psychopathology scope.

Keywords: Psychopathology; Phenomenology; Phenomenological psychopathology.

Resumen: La fenomenología en su intersección con la psicopatología fue estudiada por distintos autores en la psicología y la psiquiatría. Los estudiosos de psicopatología buscaron la fenomenología en un intento de evitar la nosología psiquiátrica clásica en sus reducciones y entendimientos indebidos, así como para adoptar una teoría humanista, con la esperanza de que presente sistemáticamente etiología, descripción, categorización, pronóstico y tratamiento de las enfermedades mentales. Dicho esto, esta comprensión es necesaria para el entendimiento de lo que se dice psicopatología fenomenológica, con la intención de definir su alcance, cobertura, constitución y propósitos. Este trabajo tiene como objetivo exhibir una introducción al estudio de la materia, teniendo en cuenta su contexto de inserción y herencia. Para esto se construyó una investigación exploratoria dese una revisión de la literatura, rescatando las perspectivas actuales de la psicopatología, señalando las corrientes predominantes y hegemónicas y proponiendo una clasificación. El enlace acerca de la noción actual de la psicopatología y el concepto de enfermedad expresó que no hay una naturaleza en el entendimiento sobre la noción de enfermedad. Posteriormente se discutió la posibilidad para nombrar a esta área do conocimiento como psicopatología fenomenológica, teniendo en cuenta la relevancia y las consecuencias de su adopción, al lado de esto se trae la intención de la realización de una reflexión sobre posibles objetivos para el campo de estudio analizado. Se concluyó que la comprensión de la psicopatología fenomenológica es un campo en evolución, requiriendo profundidad en sus delimitaciones desde la práctica de los profesionales de la salud como la reflexión pertinente sobre la fenomenología y la posibilidad de adaptación a la psicopatología.

Palabras clave: Psicopatología; Fenomenología; Psicopatología fenomenológica. 


\section{A busca da fenomenologia como forma de negar a precariedade. A restauração da precariedade}

Raramente não se verifica certo tipo de decepção no estudioso iniciante em psicopatologia fenomenológica que, descontente com a nosologia fria e rotulante da Psiquiatria clássica, sequioso por apreensão e domínio de um conhecimento dito fenomenológico, reconhece na fenomenologia o pronunciamento contra a redução do humano em perspectivas objetivantes, acenando para a possibilidade de um patamar mais humano, e ao mesmo tempo mais seguro do estudo psicopatológico. Aproxima-se esse iniciante da fenomenologia, ele mesmo negando a nosografia, mas desconhecendo estar, na verdade, em busca de princípios e regras que, à semelhança de outras perspectivas teórico-científicas, apresentem sistematicamente etiologia, descrição, categorização, prognóstico e terapêutica; bastando então para o iniciante que em sua prática clínica realize a correlação dos acontecimentos humanos prévios e relativamente padronizados com as descrições estruturadas e explícitas na teoria da psicopatologia fenomenológica, a fim de obter condução a procedimentos seguros que, por sua vez, desencadeiem a de cura. Estaria então em patamar privilegiado: sob a garantia de um suposto humanismo - subjacente ou explícito - e com a segurança de metodologia eficaz e rigorosa, ao mesmo tempo em que permaneceria afim às suas perspectivas antropológico-filosóficas e metodológicas.

Falo na decepção, pois, a fenomenologia rigorosa se pronuncia, ela mesma, contra sua interposição como conhecimento privilegiado no estudo de qualquer fenômeno, o que se aplica também ao psicopatológico (Tatossian, 2006). Recusa-se a si mesma como o conhecimento válido e prévio para revelação de perspectivas, sejam elas psicopatológicas ou de qualquer outra natureza. Ora, utilizar-se da fenomenologia como conhecimento privilegiado é operar o contrário de uma de suas mais importantes recomendações, qual seja, a suspensão do a priori (Karwowski, 2005; Tatossian, 2006), ou antes, não priorizar qualquer tipo de conhecimento quando em contato com o objeto, a fim de que possa, o próprio objeto, revelar-se em sua inteireza. É a própria fenomenologia que se proíbe de figurar como conhecimento privilegiado, pois há o humano que se revelar antes de toda e qualquer perspectiva filosófica ou científica, sendo ele mesmo quem deve reclamar perspectivas filosóficas e científicas, tornando-se assim o critério de validade desses resgates ou construções.

Logo, verifica o iniciante que a relação entre fenomenologia e psicopatologia não diz respeito a uma teoria fenomenológica aplicada às psicopatologias. Seu vínculo com estas é de implicação e não de aplicação, no sentido de que não se aplicam os conhecimentos e perspectivas fenomenológicos às ocorrências psicopatológicas. Não existem descrições específicas de cada um dos transtornos mentais, de maneira que seja possível categorizá-los em suas etiologias, prognosticá-los e oferecer terapêuticas. Se há quem assim o faça, opera opostamente a que o uso rigoroso do método fenomenológico observa. Oferece a fenomenologia, antes e, no entanto, um caminho para repensar as estruturas fundamentais do ser homem, que no seu exame e constituição revelem e impliquem aspectos psicopatológicos, ao mesmo tempo em que, ante a leitura fenomenológica das ocorrências ditas normais, sejam evocadas condições referentes às manifestações psicopatológicas. A característica essencial da fenomenologia não é apontar para nenhuma das verdades constituídas, seja pela ciência, filosofia, religião ou senso comum, e desbancá-las, relegando-as à falsidade (Karwowski, 2005), mas assegurá-las em sua condição de verdade, e também de provisoriedade, garantindo-lhes seu status para, imediatamente, as despojar da suposta condição de serem $a$ única verdade. Neste sentido, a fenomenologia aponta na psicopatologia estabelecida sua condição de verdade provisória, ao mesmo tempo em que acena para, com suporte no exame de aspectos essenciais à própria psicopatologia ou normalidade, o estabelecimento de perspectivas igualmente verdadeiras sobre o ser homem e seu adoecimento.

Percebe-se, então, que o estudo da psicopatologia numa perspectiva fenomenológica, antes de oferecer uma posição segura para intervenções nas psicopatologias, propõe reflexões fundamentais sobre aspectos ontológicos do humano que, integrados na Antropologia Filosófica específica da fenomenologia, permitam elaborações de instrumentos interventivos precisos e afinados com a cotidianidade do ser homem. Talvez, no rigor reflexivo levado a fundo e a termo pelo método fenomenológico, se produzam mais dúvidas do que certezas, mais caminhos possíveis do que vias oficiais, revelando, ele mesmo, sua semelhança com a insegurança e provisoriedade da própria existência humana. Requer, assim, emergência e admissão, nele mesmo, no estudioso de psicopatologia, daquilo que, como forma de driblar a crueza dos aspectos mais reais da existência, buscava desocultar e mitigar no outro, e que muitas vezes apenas se tornam claras pelo prévio reconhecimento em si das próprias psicopatologias.

Isso posto, posso concluir que a psicopatologia fenomenológica revela, em última instância, as condições precárias do próprio estudioso; não mais pela ausência de garantias que a detenção do conhecimento psicopatológico poderia oferecer contra a ocorrência das psicopatologias no próprio estudioso, pois essas garantias o mero estudo da psicopatologia clássica já havia feito ruir; mas pelo fato de revelar naquela normalidade segura que se supunha habitar (livre de angústias, temores e sofrimentos) a própria angústia, o temor e o sofrimento, não como estruturas supostamente psicopatológicas, mas como elementos ontológicos, logo, inarredáveis da existência humana. 
Assim, tal estudo, mais do que meramente exprimir qualquer estrutura psicopatológica, impele o estudioso à descoberta de formas para o convívio com essa precariedade sempre presente, para, daí mesmo e com ela, criar instrumentos que ele terá de utilizar e abandonar ao longo do caminho, sob pena de "encantar-se mais com rede que com o mar" pretendia libertar.

Psicologia fenomenológica: Permito-me afirmar que o campo de estudo chamado "psicologia fenomenológica" é ainda impreciso, e carece de elaborações rigorosas. Tivemos nos últimos anos importantes elaborações acerca de uma psicologia husserliana (Goto, 2008), ou de uma dita psicologia kierkegaardiana (Feijoo, 2011, 2013), além de procedimentos que aproximam a utilização dos princípios e do método fenomenológico à área psicológica (Forghieri, 1993; Holanda, 2002; Karwowski, 2005; Giorgi, 2009, Amatuzzi, 2009, 2011, apenas para citar alguns). No que concerne à utilização dos princípios heideggerianos para um reexame da psicopatologia, autores como Ludwig Binswanger e Medard Boss fizeram importantes exames e contribuições, conforme o citado por Holanda (2011) em seu resgate da história da psicopatologia fenomenológica, muito embora a utilização da filosofia heideggeriana por autores contemporâneos seja controversa (Stein, 2006) e não sem motivos. Na maioria das vezes, tal pensamento é pouco compreendido e, com recorrência, assemelha-se mais a um receituário (na tentativa de utilizar-se do método fenomenológico ou pensamento heideggeriano) ou a reflexões existencialistas romantizadas, do que a uma rigorosa reflexão sobre as estruturas do ser homem e sobre a possibilidade do aporte conceitual da ontologia heideggeriana como fundamentação científica.

A exemplo do que acontece com a arte, sendo ela, e nela a poesia, um importante caminho de acesso à verdade, sua figuração, quando convocada a se imiscuir no descobrimento humano (que a ciência reclama) e, principalmente, quando não é suficientemente levada a termo, ou seja, não produz o exame aprofundado em suas relações com o ser homem, conduz à banalização da própria arte, reduzindo-a à mesmidade, quando não à igualdade, pois não se recobrou suficientemente a mesmidade necessária como condutora à novidade (Heidegger, 1930/2006). Da mesma maneira, a referência à ontologia heideggeriana no campo psicológico implica necessário exame do ser homem e suas possibilidades de revelação, especificamente naquilo que o campo psicológico demanda, inclusive na distinção suficiente entre o psicológico e filosófico (Stein, 2006).

Em que instância, pois é possível, falar em uma psicologia fenomenológica? Não se trata aqui de um profundo exame epistemológico da Psicologia, a fim de se determinar em que condições poderia a este saber se servir de tal

\footnotetext{
Parte da música "Lua e Flor" de Oswaldo Montenegro, Long Play: "Brincando em Cima Daquilo" (1984), Gravação: Phase Studio (RJ).
}

e qual fundamentação filosófica, visto ser, antes de mais nada, ela mesma, a Psicologia, livre para buscar qualquer fundamentação que possa entender como válida para o aprofundamento em seu objeto, mas sim de apontamentos em torno de uma estrutura dita científica, bem como da necessidade de proximidade rigorosa entre um pensamento filosófico e a Ciência Psicológica.

O primeiro apontamento, tal como mencionado, diz respeito à relação estabelecida entre o estudioso de fenomenologia e a Psicologia. Da mesma maneira que a mera transposição de um país não possa necessariamente implicar a afirmação sobre seu conhecimento, a mera utilização de conceitos fenomenológicos aplicados, seja à psicologia, seja à psicoterapia ou a psicopatologia, não implica necessariamente na sistematização de um campo chamado de Psicologia fenomenológica, mesmo que os benefícios desse uso conceitual ou ainda dessa aproximação metodológica sejam inegáveis (Tatossian, 2006). É verdade, porém, ser possível estabelecer diferença entre um estudioso que conheça a história da fenomenologia e outro que seja senhor da teoria da fenomenologia, e ainda aquele versado em metodologia fenomenológica. Também há que se distinguir, no entanto, a excelência daquele que reúna esses conhecimentos e, sobretudo, saiba fazer leituras fenomenológicas sobre seu objeto de estudo, revelando as verdadeiras relações originárias homem-mundo no que tange à especificidade daquilo a que se refere; ou seja, consiga examinar objetos simples do cotidiano (tais como copos, canetas ou mesas), objetos abstratos (cubos e círculos geométricos, p.ex.) fazendo-lhes também leituras fenomenológicas, mas, também e principalmente, possa olhar objetos referentes à sua área de estudo (como, no caso da Psicologia, a solidão, o psiquismo, a saúde mental, a própria psicopatologia) e também aí realizar leituras fenomenológicas, que revelem a estrutura originária homem-mundo.

Outro apontamento diz respeito à necessidade do desenvolvimento de arcabouço conceitual, afim com a Filosofia de base, não porque sua teoria foi aplicada ao objeto psicológico, mas porque se faz necessária uma fenomenologia do psiquismo, uma do desenvolvimento humano, outra da personalidade, da psicopatologia, e também dos tratamentos possíveis correlatos a esses exames psicopatológicos; ou de outras dimensões que se façam necessárias para o estabelecimento de uma chamada Psicologia. Tais procedimentos revelariam mesmo a possibilidade ou impossibilidade da conjugação da Psicologia com a Fenomenologia, implicando, portanto, uma ação transposta a uma Psicologia, como, por exemplo, aquela explícita por Sartre em “O Ser e o Nada” (1943/2007), ou ainda do necessário, mas ainda insuficiente reconhecimento de uma psicologia em Husserl. Tais atos implicam uma elaboração conceitual para se considerar as categorias fundamentais da fenomenologia em sua articulação com as tarefas da Psicologia, ainda que para isso se tenha que construir uma nova Psicologia. 


\section{0 conhecimento com origem em Heidegger}

Último e importante apontamento diz respeito ao processo de elaboração do conhecimento, exaustivamente examinado pela Filosofia da Ciência, onde a elaboração heideggeriana teve um papel de desconstrução do entendimento do saber até então realizado.

A importância do entendimento dessa formulação do conhecimento diz respeito ao fato de que as concepções pertinentes ao âmbito do conhecimento não se mantêm restritas às discussões acadêmicas e ao locus filosófico, pois se tornam orientadoras da cultura e constituintes do entendimento antropológico e cosmológico, assim como orientadoras das concepções científicas, hoje críveis como privilegiadas na definição das ditas verdades cosmológicas e antropológicas. É, então, com hipótese nessa imbricação que se constituíram também as ciências humanas, as quais embora se propusessem examinar em profundidade a especificidade de seus objetos, todos eles humanos, são caracterizadas pela ausência de aberta interlocução que comprove a consideração do ser humano como integrado e íntegro. Por conseguinte, toda a elaboração do conhecimento dito científico herda a característica cisão sujeito-objeto e seu ideal empirista-positivista de realização de modelos científicos.

Com o surgimento da fenomenologia e do conceito de intencionalidade, o binômio sujeito-objeto é re-unido em sua fundamental constituição, ficando a cargo de Heidegger (1927/1993) a inauguração de uma metafísica correspondente a seu terceiro período histórico, melhor dita como ontologia. Nessa fase da metafísica, o critério de verdade não mais repousa no sujeito ou no objeto em sua independência ou cisão epistemológica, mas na relação originária homem-mundo, identificada como Dasein, condição em que a verdade será ao mesmo tempo constituidora do conhecimento e da realidade a que se refere.

O deslocamento da cisão para a relação originária homem-mundo como fonte da formulação do conhecimento levou a desdobramentos importantes para a concepção de todo e qualquer conhecimento, de sorte que se possa então, perguntar: haverá mesmo a possibilidade de formação de uma psicologia fundamentada nessa concepção heideggeriana?

A despeito da resposta positiva ou negativa a esta indagação - pois até aqui minha reflexão é ainda incipiente - formar, pois, uma concepção de Psicologia fenomenológica efetivamente implicará a escolha de pelo menos um dos caminhos: a) examinar como se têm utilizado os psicólogos da conjunção entre fenomenologia e psicologia, a exemplo do que fez Tatossian (2006) quando expressou a Fenomenologia em conjunção com a psiquiatria, segundo suas palavras "como a tem feito os psiquiatras e não como deveria ser realizada" (p. 23, $1^{\circ} \S$, grifos nossos); b) reaver os princípios norteadores de um tal pensamento fenomenológico, malgrado filósofos fenomenólogos e a pertinência de suas ideias à Psicologia, com amparo no que eles mesmos consideraram como pertinente, e, para além disso, com apoio no que se pode fazer baseado em suas elaborações e restrições em face das necessidades da Psicologia mas, sem lhes negar a fidelidade epistemológica que faz jus ao que apresentam eles mesmos suas objeções ou dificuldades a uma transposição; c) realizar exames rigorosamente fenomenológicos (no que concerne à metodologia destes) sobre as temáticas fundamentais da Psicologia em sua constituição como campo de explicação, compreensão e intervenção no real.

Possivelmente em relação a esses dois últimos itens, outra formulação da psicologia se fará necessária, malgrado, por exemplo, as considerações feitas por Stein (2006), quando pensa a Filosofia e o conhecimento empírico, demonstrando a impossibilidade de se estabelecer esse empírico desde perspectivas heideggerianas, por não haver fundamento conceitual suficiente para o objetivo de se estabelecer o conhecimento empírico em um outro pensar.

\section{0 pensar em Heidegger}

Sendo assim, em que condições é possível situar a elaboração heideggeriana? Como se conjuga com o conhecimento empírico? No exame da obra heideggeriana, distinguem-se efetivamente três fases de seu pensamento, chamadas de Heidegger I, II e III², embora se saiba que "não existe três Heidegger. Foi a procura de uma compreensão das etapas de sua obra monumental e de seu projeto imanente que levou à criação do Heidegger I, II e III". (Stein, 2006, p. 28). Melhor então se falar em fases do pensamento heideggeriano de acordo com sua coerência interna.

A primeira fase, chamada do Heidegger I, é a referente a suas elaborações anteriores a Ser e Tempo $(1927: 1993)^{3} \mathrm{e}$ que aparecem nessa obra de maneira sintetizada, além da produção posterior, resultante como consequência imediata de ST. É nesse período que acontecerão os vários passos para situar a analítica existencial como ontologia fundamental. O Heidegger II constitui o momento da viravolta, Kehre, onde se nota a necessidade de abandonar o elemento transcendental em favor da dimensão historial. Inwood (2002) se referirá à virada não como uma mudança de opinião ou ponto de vista, mas como a operação de uma mudança interna de direção para se confirmar o pensamento do próprio autor ou para melhor se caracterizar a compreensão do problema. Trata-se de um processo guiado pela destruição e superação da metafí-

\footnotetext{
2 Outros autores falarão em um "Heidegger Tardio", ou em um último Heidegger em contraposição ao jovem Heidegger. A esse respeito, ver especialmente Pattison (2001). Optei por manter neste texto a distinção feita por Stein (2006), por entender que se apresenta como mais pertinente para o tema focalizado.

Utilizarei a notação "ST" para me referir à obra "Ser e tempo" de Heidegger (1927/1993).
} 
sica onde se faz um exame que vai de Hegel aos gregos, elaborando também outro movimento dos pré-socráticos até a Filosofia do século XX. Efetivamente, temas ligados à cultura, ao poder, ao ser humano e aos múltiplos desdobramentos das ciências no fenômeno da técnica aparecem em ST como maneira de organizar teoricamente a questão do esquecimento do ser. Nas obras dos anos 30, as temáticas referentes a arte, técnica, poesia, imagem de mundo, função das ciências e outros temas, constituem a busca da superação da metafísica, tendo seu encerramento nas preleções sobre Parmênides e Heráclito. O Heidegger III pode ser chamado de um filósofo da contemporaneidade, em que a condição humana em geral, as questões específicas da ciência e da cultura são examinadas em uma dimensão que a Filosofia sempre tentou ocultar. Essas temáticas são consideradas como retomada de seu pensamento, mas também como maneira de respostas aos problemas da humanidade do século XX. Aparece, pois, como espécie de guia que leva à filosofia da analítica existencial (Heidegger I) e à filosofia do esquecimento do ser (Heidegger II), pois sua consideração efetiva revela a obra do Filósofo como um todo.

Embora o Heidegger II se ocupe com a temática do pensar, é no Heidegger III que existe a diferenciação de três formas de pensar, sendo ao mesmo tempo a aplicação de sua filosofia ao próprio pensamento. É na obra Que significa pensar? (Heidegger, 1954/2005) que Heidegger apresentará a distinção entre essas formas de pensamento e que afirmará que a "ciência não pensa”. Resumidamente é lícito acentuar que, da forma como apresentado por Martin Heidegger, o "pensar" I se refere àquela forma de pensamento que constitui o pensamento empírico; o "pensar" II consiste no estabelecimento de regras e condições formais que vêm da Lógica; e o "pensar" III se constitui no pensar da diferença ontológica. É este "pensar" que Heidegger afirmará se constituir a Filosofia, fazendo sua distinção entre o pensar da metafísica e o pensar da ciência. Essa diferença ontológica não se refere apenas à separação entre ente e ser, mas à relação estabelecida entre ente e ser por intermédio do único ente capaz de se perguntar pelo ser, ou seja, o Dasein. Constitui-se, logo e assim, no acontecimento do ser, mas também no contexto do ser. É dessa maneira que se estabelecem na filosofia da finitude de ST os dois teoremas fundamentais, o círculo hermenêutico e a diferença ontológica (Stein, 2006).

A fenomenologia hermenêutica evidencia o fato de que o acesso ao conhecimento científico e seus objetos terá como condição de possibilidade o processo de pré-compreensão, que desde sempre acompanha o ser-aí. A consequência fundamental será a emergência de um vínculo entre o pensamento e o modo de pensar científico, sustentado pela diferença ontológica. Neste passo, o principal perigo refere-se a cair nas armadilhas da objetificação, possíveis tanto no que se refere à Filosofia quanto no conhecimento científico na referência de seus objetos.
Contrastando com o pensamento científico da forma como atualmente estabelecido, os caracteres ontológicos do humano o lançam em outra dimensão que nem a linguagem, tampouco os procedimentos técnicos da ciência alcançam, em decorrência da sua imersão na dualidade e separação homem-mundo. Ora, é exatamente pelo reconhecimento de aspectos concernentes à ontologia que as possibilidades de resgate do ser em geral e, por conseguinte do ser humano se darão, em que a finitude terá caráter primordial:

Por fim, tudo o que se possa discutir sob a rubrica de uma 'metafísica da morte' extrapola o âmbito de uma análise existencial da morte. As questões de como e quando a morte 'entrou no mundo', que 'sentido' de mal e sofrimento a morte pode e deve ter na totalidade dos entes não apenas pressupõem, necessariamente, uma compreensão do caráter ontológico da morte, como também a totalidade dos entes em seu todo e, em particular, o esclarecimento ontológico do mal e da negatividade (Heidegger, 1927/1993, p. 30, $1^{\circ}$ §)

Ao reconhecer o homem como um ser-para-a-morte, Heidegger recupera a finitude não apenas em seu caráter essencialmente humano, mas também a insere em outra ordem de pensamento, ou melhor, concede à filosofia a possibilidade de pensar com origem noutra ordem reflexiva, pois, na conjugação entre ser e não-ser, a finitude adquire sentido radicalmente diferente daquele expresso pela tradição filosófica (Stein, 1976).

Enquanto o homem permanecer enredado na metafísica, ou seja, enquanto ele se ativer ao primado do ente como o efetivamente real no sentido do efetivante e "poderoso" (o que é capaz do efeito), o nada permanecerá o que não é digno de nada. E o terror, como a tonalidade efetiva fundamental descerradora do nada, permanecerá aquilo que não merece senão resistência e o desprezo como um dano para toda afirmação da "vida". E, inversamente, enquanto esse desprezo do nada se mostrar como elucidativo e encontrar a mais imediata concordância, o homem permanecerá no esquecimento do ser, quer dizer, naquela não relação com o ser que o impede de dignificar o presente da "negatividade" e mensurar a determinação da humanidade, adentrando, assim, no espaço-de-jogo-temporal das decisões simples. (Heidegger, 1930/2010, p. 237).

Nessa tradição, desde os gregos até os filósofos cristãos, o infinito (Deus) foi considerado como perfeito, bom e positivo ou fonte de toda a positividade. Por sua vez, o finito havido como imperfeito, mau e negativo ou dotado de toda negatividade. O ser depende do não-ser, mas, na tradição cristã, a interpretação do não-ser o subjuga ao Ser Supremo, fazendo com que o finito tenha todo o 
caráter de negatividade perante o infinito almejado, que deve então ser referência para se ultrapassar os limites e então se aproximar do perfeito. A consequência desse pensamento é a redução do não-ser como constituindo fonte de toda negatividade e toda negatividade como ausente do ser ou de positividade. Heidegger recobra a noção de finitude como ontológica:

O pleno conceito ontológico-existencial da morte pode agora se delimitar da seguinte maneira: Enquanto fim da pre-sença, a morte é a possibilidade mais própria, irremissível, certa e, como tal indeterminada e insuperável da pre-sença. Enquanto fim da pre-sença, a morte é e está em seu ser-para o fim (1927/1993, p. 41, parte II).

Assim, da finitude como ontológica, extrai a possibilidade de doação de sentido ao Dasein, requerendo também a possibilidade de todo finito como não necessariamente negativo, mas do negativo como possibilidade de doação de positividade.

Sabidamente, a tradição do conhecimento não entra por essa via denunciada por Martin Heidegger. É do conhecimento fundado na positividade como exclusivamente positiva e na negatividade como exclusivamente negativa que surgiram as concepções de conhecimento. É nesse sentido que aqui pergunto: haveria possibilidade de se estabelecer o conhecimento empírico na noção de finitude heideggeriana? Essa ideação de finitude poderia ter inaugurado procedimentos filosófico-científicos nos quais fossem considerados nas ontologias regionais aspectos da negatividade como fonte de positividade? Em que condições a finitude como ontológica pode recuperar, por uma via não ontoteológica, a articulação entre ser e não ser?

Tendo esses aspectos levados em conta e da maneira como se poderão estabelecer as respostas a tais questões, entendo que houve uma passagem da filosofia da infinitude a uma filosofia da finitude tal como posta por Martin Heidegger. A filosofia do infinito tornou-se um impeditivo para apropriação do conhecimento do ser humano em sua ontologia. $\mathrm{O}$ exame da possibilidade de estabelecimento de uma nova forma de pensamento fundamentada na ontologia da infinitude se justifica pela possibilidade de contribuir para importantes desdobramentos na elaboração do conhecimento, com importantes consequências para as ditas ciências humanas, no que se refere a seu estabelecimento em "um outro pensar", logo, com mudanças no objeto e nas metodologias de acesso e interferência nesse objeto. Irremediavelmente ligadas a uma antropologia filosófica, as ciências humanas se estabeleceram fundamentadas em uma tradição filosófica da cisão e da busca do infinito como possibilidade de superar a condição humana. Seus procedimentos técnico-científicos são submetidos à concepção do ser em geral e à ideia do ser humano oriundo das concepções filosóficas disponíveis à época de sua fundação. Um estudo como proposto há pouco poderá contribuir para a possibilidade do estabelecimento seguro de uma filosofia da finitude como fundante de um novo conhecimento, passível de, assim, se contribuir para o reestabelecimento das ditas ciências humanas.

A consideração de uma psicologia fenomenológica, como sucedânea ao pensamento heideggeriano tal como exposto em instantes, implica sim a identificação do que fazem e como fazem os psicólogos na conjunção da Psicologia com sua fenomenologia, mas para muito além, na verificação da correlação dessas elaborações com o tipo de pensamento de Heidegger, bem como com a consideração, principalmente, da não contradição com a necessidade de superar a dualidade homem-mundo e o esquecimento do ser. Parece-me que tais ações ainda estão em curso, lançando ainda toda elaboração empírico-conceitual com procedência em Heidegger, num patamar ainda inseguro, carente de reflexões e de elaborações que se oponham e contraponham a essa empiria vigente, confirmando então o caminho indicado por Martin Heidegger.

Posso então asseverar que a busca da fenomenologia para se estudar a psicopatologia deve se estabelecer não como uma forma de se negar a precariedade do conhecimento clássico de psicopatologia, muito menos em substituição a ele, mas para se afirmar sua precariedade e também para se reconhecer e asserir a precariedade de todo e qualquer conhecimento vigente para respostas definitivas aos fenômenos psicopatológicos. A fenomenologia revela, ela mesma, a precariedade do próprio estudioso, sendo talvez essa a mais possível via de compreensão dos fenômenos psicopatológicos: a constatação da vigência da doença não apenas no dito doente, ou da saúde no dito médico, mas sua concomitância, em modos distintos, em ambos os parceiros.

\section{A herança psicopatológica}

O olhar aprofundado para a psicopatologia como campo de estudo revela que a noção de psicopatologia vigente não predomina desde tempos mais remotos da humanidade; ou seja, o entendimento atual dos fenômenos ditos psiquiátricos como doença mental não é um entendimento que permaneceu igual ao longo do desenvolvimento da humanidade. Os manuais de Psicologia e de Psiquiatria exprimem as várias fases por que passou o entendimento do que hoje se chama doença mental, desde sua concepção religiosa, mediante a qual se entendia o fenômeno psiquiátrico como endemoninhamento, até sua concepção científica como doença mental. E é exatamente essa circunscrição como doença que a mim interessa aqui, não ainda exatamente na sua forma vigente, mas na pertinência às várias noções que o fenômeno doença adquiriu ao longo da história da humanidade. 
Quer sob a perspectiva histórica, quer sob visão etimológica, na "psico-pato-logia” que se apresenta como estudo das doenças mentais, é a força do pathos que a circunscreve e doa seu sentido. O "Pathos" que integra o termo psicopatologia não possui um sentido único de doença, tal qual disseminado na Ciência biomédica (Martins, 1999), embora seu sentido atual seja prioritariamente o estudo da doença.

Sendo previamente remetida ao desenvolvimento da noção de doença que, por sua vez, não é natural, mas coextensiva à história da humanidade (Ramos, 1994), duas observações importantes estão implicadas nessa afirmação. A primeira diz respeito ao cuidado de se evitar reificações. O termo reificar adquire aqui o significado preciso de se transformar processos complexos em objetos do conhecimento que, quando nomeados, adquirem status de independência e são objetificados, quase existentes por si e independentes do humano, estando assim coisificados, quase tangíveis e existindo por si mesmos. Assim é que a concepção de doença corresponde à nomeação de um processo amplo e complexo, constituído historicamente e submetido à noção de conhecimento em voga, responsável ele mesmo por dizer o que é a realidade e como se pode conhecê-la e nela interferir. A segunda observação aponta novamente para a necessidade de se romper com a atitude natural ou com a tendência a tornar natural aquilo que possui significados e representações não apenas históricas, mas afim às diversas noções que a sociedade faz de si mesma e do mundo, nesse caso, especificamente, da origem e da causa do mal relacionadas às doenças. Como rigorosa deriva, a psicopatologia herda sua concepção das noções de patologias, constituindo-se também, e principalmente ela, não como natural, mas como histórica. Para então se examinar noções de psicopatologia, faz-se necessário compreender o dinamismo ou pelo menos a mudança histórica da noção de patologia a que a própria psicopatologia está ainda circunscrita, estando por isso mesmo influenciada por compreensões etiológicas, prognósticas e terapêuticas de seu paradigma originário.

Antropologicamente, a representação mental de doença mostra-se segundo dois eixos distintos (Bucher, 1989) sob os quais oferece o entendimento ou a compreensão humana acerca da doença. O primeiro deles, denominado como ontológico, por sua construção filosófica, e segundo a qual procura abordar o ser das coisas, "ao longo de percursos especulativos, místicos ou religiosos" (p. 10, $\left.2^{\circ} \S\right)$. A concepção ontológica representa a doença como referente a um mal de origem misteriosa e cósmica, universal ou local, impondo-se como um impedimento da busca humana para a felicidade e autodeterminação, ou seja, a capacidade para decidir e projetar-se em direção ao próprio futuro. Subjaz a esse entendimento uma axiologia que dividirá o mundo entre perspectivas polares e conflitantes provenientes da ideia de bem e de mal. Essas estão em eterno conflito, sendo inevitáveis para o homem, ao mesmo tempo em que se expressa, ele mesmo, como o lócus onde a luta se desenvolverá eternamente e independentemente de sua vontade, pois esse conflito é inerente à natureza, que se caracteriza como animista, tanto em relação a seres humanos quanto a espíritos ou forças mágicas de origens diversas. O segundo eixo faz referência à figuração da doença como algo pertinente ao mundo do "ter" - em oposição à primeira, pertinente ao mundo do "ser" - vinculando-se a condições mecânicas e causais, numa clara referência ao Zeitgeist prevalente no surgimento da ciência. Esforça-se nesse eixo para considerar a doença como resultante de causas objetivas e verificáveis que, com o avanço tecnológico, se tornam cada vez mais isoláveis e factíveis de objetivação.

Tais formulações advêm das elaborações filosóficas em torno da noção de ser e não-ser, segundo as quais se constituiu para o ser toda condição de positividade e para o não-ser toda condição de negatividade. Como já mencionei linhas atrás, a deriva dessas elaborações, originárias em Platão e Aristóteles e reinterpretadas pela Filosofia cristã (Stein, 1976), permitiram não apenas um pensamento ocidental dicotômico, mas também a impossibilidade de se refletir o negativo do positivo ou o positivo do negativo. Evidentemente, essas noções estão também relacionadas a outras elaborações polares, figurantes como igualmente dicotômicas, como, por exemplo, a noção de dentro e fora, a ideia de eu e não eu, que se imiscuem na formulação do conhecimento científico e contribuem para toda sorte de confusão entre mundo humano e mundo material, dicotomias estas que, se por um lado se apresentam como a única possibilidade de se estabelecerem diferenciações, de outra parte se expressam como impeditivas da recuperação não apenas da necessária interdependência entre ser e não-ser, mas também da necessária e mútua constituição do ser pelo não-ser e vice-versa. $\mathrm{O}$ exame em profundidade dessa reflexão não pode ser realizado aqui.

Como uma das consequências, é divisada na história da Medicina uma oscilação entre os eixos ontológico e mecanicista, não tendo o segundo jamais conseguido prevalecer ou suplantar totalmente o primeiro (Canguilhem, 1966/2002). São encontradiços no âmbito das pesquisas tecnológicas mais puras, ou no cerne das práticas médicas mais avançadas modelos ontológicos que supostamente seriam contrários às teorias mais esclarecidas. Como consequência, as chamadas crenças etiológicas universais (Bucher, 1989) estão enraizadas na complexidade das representações ontológicas da doença. A primeira dessas crenças, identificada como exógena, aditiva ou centrípeta, concebe a doença como a ocorrência de algo a mais no paciente, por exemplo, um agente patológico, que lhe deve ser retirado. A segunda concepção, denominada endógena, deficitária e centrífuga demonstra o paciente como quem sofre da falta de alguma coisa que lhe foi retirada, tendo, portanto, e em oposição à primeira, "algo a menos" e que lhe deve ser reposto. 
Faço aqui uma observação sobre a ideia de ontologia esposada pelos autores citados, chamando a atenção para a mera utilidade do termo para se referirem ao ser da doença, não implicando, pois, rigorosa apreensão de sua concepção ontológica tal como, por exemplo, e privilegiadamente elaborado por Martin Heidegger. Nessa concepção, tanto a perspectiva mecanicista como a dita ontológica diriam respeito à ontologia heideggeriana, pois fazem referência ao ser categorial, ou seja, à essência ou natureza do existente.

Não obstante as representações mentais possíveis de se fazer da doença, fala-se então em modelos ou paradigmas de saúde-doença, apontados como representativos da relação cosmológica e até mesmo da noção que se faz do cosmo. Dessa forma, uma maneira de se considerar essa elaboração diz respeito à ideia de união ou à unidade cosmogônica, no qual o ser humano se concebia como intimamente ligado ao mundo, se indiferenciando em relação à natureza, e, como consequência, estabelecendo relações mais integradas e integradoras, tanto com seus semelhantes quanto com a própria cosmologia onde esses semelhantes se inseriam. Ramos (1994) oferece então cinco noções a que chama de "modelos" e que aqui prefiro chamar de paradigmas por se se assemelharem mais ao modelo amplamente aceito que a ciência explicita em suas considerações, quais sejam, o paradigma primitivo, o grego, o cartesiano, o romântico e o biomédico. Evidentemente, o exame aprofundado desses modelos revelará a inexistência de sistemas puros, mas elementos que se conservam, se justapõem e se refutam, permanecendo sempre resquícios de uns nos outros, mas distintos o suficiente para se identificar uma predominância e até mesmo hegemonia de uns sobre outros. Descreverei brevemente essas noções, sendo que o leitor interessado poderá se remeter ao texto original e suas indicações, a fim de aprofundar e ampliar suas pesquisas. Aqui me interessa, basicamente, a verificação da mudança na constituição do que se considera "doença" e a consolidação de uma noção científica que hoje se faz hegemônica, mas suficiente para apontar a não naturalidade do conceito de doença.

No paradigma ou modelo primitivo, as doenças pertenciam ao domínio dos deuses e do sobrenatural, ao qual somente os xamãs tinham acesso; havia uma integração homem-mundo radical, de forma que não se verificava essa distância ou afastamento entre o homem e o seu mundo. Tratava-se antes de se reconhecer a diferença, não a descontinuidade. Dessa maneira, a doença era entendida como perturbação do mundo dos espíritos que teria ocorrido por alguma ação ou atitude, por parte daquele que manifestava o fenômeno hoje entendido como doença. O "tratamento" implicava desde a ingestão de ervas até a mudança de comportamentos ou de pensamentos, sempre acompanhados de rituais cuja determinação e condução ficavam a cargo do xamã. Importante é salientar a compreensão da doença como pertinente ao mundo espiritual e de sua responsabilidade, tanto na manutenção quanto na cura, dependendo da interferência que os vivos poderiam fazer em relação à espiritualidade. Fácil é depreender que a compreensão de doença não dizia respeito ao que propriamente chamamos doença, mas a ocorrência de um mal que deveria ser encarado com recursos de ordem espiritual. Aquilo a que se chama modelo grego diz respeito à forma como os gregos lidavam com o que hoje entendemos como doença. Nessa época, foram introduzidas a separação corpo-espírito e a formulação do método de observação, análise, dedução e síntese. Junto com os primórdios metodológicos, bastante distintos da forma em que hoje é entendido o método, há também o estabelecimento da separação homem-mundo que culminará bem posteriormente com o cogito da filosofia moderna, sugerido por Descartes. Cumpre ressaltar que, embora na concepção grega seja iniciada a cisão homem-mundo, a doença era constituída em ampla inter-relação homem-mundo, cujo elemento diagnóstico dizia respeito muito mais à escuta, e seu tratamento implicava mudanças alimentares, de comportamento e até mesmo troca de local de moradia. Com o modelo cartesiano, o racionalismo atinge o apogeu, sendo a razão aquela que impõe a condição de só aceitar o conhecimento verificado pelo intelecto. Não obstante, haver vários modelos de ciência (Chauí, 2000), a ênfase racionalista permeia toda sua epistemologia, tendo como corolário racional a divisão do corpo e do intelecto, aspecto suficiente não só para o surgimento da Psicologia como ciência (Schultz \& Schultz, 1994), mas também para sedimentar a separação homem-mundo. É nesse sentido que a doença é concebida objetivamente, sendo elaborada como de origem externa (agente patogênico ou trauma) e de procedência interna (disfunção ou desequilíbrio mutacional). Dessa maneira, é lícito, então, falar em causa e explicada em função de seus determinantes. O modelo romântico é uma forma de reação ao status empírico-racional da noção de ciência. Nessa concepção o estado de saúde era atribuído à interação de diferentes fatores e o racionalismo era contestado com a descoberta da irracionalidade da psique. O tratamento implicava atuações em diversos âmbitos, como o espiritual, o biológico, o psicológico e o social. Essa concepção é intitulada de romântica, tanto por pretender uma atuação global ou na totalidade, como também por implicar procedimentos considerados fora da realidade. O modelo biomédico (científico) sob cuja égide se está no momento tem como marcas principais o determinismo, a mensuração e o universalismo. Essas características são facilmente verificáveis mediante um exemplo hipotético, mas nem por isso distante da realidade de qualquer ser humano. Supondo-se haver um grupo qualquer onde alguém "passe mal” o médico ou paramédico, não tendo qualquer outro sinal evidente, inicia seu trabalho pela verificação dos sinais vitais. Tal procedimento está fundamentado no entendimento de que existe um padrão de funcionamento biológico (universalismo) humano, 
no qual todos devem estar inclusos. Essa noção assenta-se na mensuração pré estabelecida e suficiente para se considerar verdadeira tal ocorrência para todo e qualquer ser humano. Isso indica o caráter mensuralista, mas está também presente na contagem de batimentos cardíacos, verificação de pressão e taxa respiratória. A não ocorrência da padronização implica algum tipo de complicação cuja causa deve ser elucidada. Nessa perspectiva, toda intercorrência (patológica ou não) possui uma causa. Se a causa não é evidente, não é porque inexiste, mas pelo fato de ainda não ter sido descoberta.

\section{A diversidade de perspectivas em psicopatologia}

Considerando-se o modelo biomédico, a temática da doença mental já foi significativamente examinada por autores de nomeada, como Foucault (1961/1978, 1962/1984a, 1963/1984b) e Canguilhem (1966/2002), só para citar dois dos mais expressivos, e não é objeto ou propósito deste trabalho sua retomada ou discussão. Cumpre ressaltar, no entanto, que as noções de determinismo, mensuração e universalismo estão presentes tanto na criação da Psiquiatria, como na da Ciência psicológica, encarregadas historicamente de levar a termo o entendimento e a mitigação das doenças mentais.

Ao longo da relativamente curta história das ciências psicológicas e psiquiátricas, foram estabelecidas noções de psicopatologia que, ao mesmo tempo, revelam a impossibilidade de redução da doença mental a uma perspectiva unívoca e denunciam a diversidade da compreensão do entendimento do que é o homem, noção essa que estará na base epistemológica de cada uma delas e direcionará seus esforços para elaborações sobre a doença mental. A hegemonia do modelo biomédico de ciência, a supremacia da psicopatologia não teórica explícita nos DSMs - Manual Diagnóstico e Estatístico dos Transtornos Mentais (American Psychiatric Association, 1994) - somadas à sua adoção sistemática, fazem parecer existir, até mesmo para os psicólogos e psiquiatras mais comprometidos com o rigor técnico, uma só noção de psicopatologia, o que não se faz verdade.

Existem, atualmente, pelo menos 16 noções psicopatológicas que, por serem, em sua maioria, originárias do modelo biomédico, permitem a confusão entre elas e facilitam sua fusão numa concepção pouco precisa denominada muitas vezes de clássica, contribuindo para que escapem suas nuances e diversificações. Assim é que Ionescu (1995) cataloga 14 perspectivas de psicopatologia ou 14 maneiras distintas de se compreender e tentar abordar a doença mental: a psicopatologia ateórica, a psicopatologia behaviorista, a psicopatologia biológica, a cognitivista, a desenvolvimental, a ecossistêmica, a etnopsicopatologia, a etológica, a existencialista, a experimental, a fenomenológica, a psicanalítica, a psicopatologia social e psicopatologia estruturalista. Posteriormente, Moreira
\& Sloan (2002), com propósito distinto, apontarão para cinco noções de psicopatologia, a saber: psicopatologia geral, psicopatologia fundamental, etnopsicopatologia, psicopatologia social e psicopatologia crítica.

Podem então ser considerados, com base no exame da categorização proposta por esses autores assim como com arrimo na exposição dos paradigmas de patologia ora expostos, os seguintes pontos: a) a atual noção de psicopatologia é, senão pertinente, relacionada a um status de patologia eivado de dicotomias ou mesmo antinomias, dentre elas e, por exemplo, a cisão corpo-mente; b) a última autora citada conserva três noções anteriores citadas por Ionescu e acrescenta outras duas, somando-se então e, como dito, 16 perspectivas acerca da psicopatologia, o que demonstra a possibilidade de surgimento de ainda outras; c) não há uma noção de psicopatologia suficiente para agrupar, suplantar ou integrar as anteriores; d) as atuais elaborações realizadas pela ciência não conseguiram integrar as noções psicopatológicas, provavelmente em decorrência da noção multifacetada do que é o homem, pois, conforme sublinha Vaz (1992), cada ciência tenta adotar a noção de homem que lhe dê o lugar mais privilegiado para assim construir seu conhecimento; e) a psicopatologia fenomenológica, objeto deste trabalho, está inserida dentro do rol de noções citadas e também não parece representar a suficiência mencionada no ponto c.

Expresso a seguir uma proposta de agrupamento das diversas perspectivas indicadas pelos autores citados, considerando suas proximidades epistemológicas ou ênfases, seja na formulação teórica (objetivos, metodologia ou técnicas), seja na elaboração de sua filosofia antropológica. A noção de perspectivas aqui adotada não implica rigidez categorial, nem reclama a constituição dessas perspectivas em "matrizes" de pensamento, por não se perceber necessariamente a geração de outras distintas noções psicopatológicas desde as das perspectivas expostas. Por outro lado, a ideia de perspectiva implica sempre numa construção do conhecimento em aberto e dinâmico, que pode ser revisto continuamente, representando assim meramente um ponto de partida, ou um campo do saber de onde se parte para se abordar algum tema.

Perspectiva ateórica - o critério para agrupamento dessas perspectivas diz respeito ao fato de se pretenderem mais livres de influências teóricas, sendo elas a $p s i-$ copatologia ateórica e a psicopatologia geral.

Perspectiva objetivista - essas perspectivas tendentes à reprodução rigorosa de princípios científicos e objetivantes do humano; assemelham-se entre si tanto na constituição metodológica, quanto no critério de resultados, sendo elas a psicopatologia behaviorista, a psicopatologia experimental e a psicopatologia cognitivista.

Perspectiva etológica - o critério para agrupamento diz respeito à similitude entre caracteres biológicos ou a redução aos aspectos biológicos - a psicopatologia biológica e a psicopatologia etológica. 
Perspectiva desenvolvimentista - traz como central uma noção de desenvolvimento ou crescimento "desenvolvimental", sendo elas a psicopatologia "desenvolvimental" e a psicopatologia ecossistêmica.

Perspectiva estruturalista - prima pela busca de estruturas indicadoras da constituição psicopatológica.

Perspectiva social - remete a existência da psicopatologia às constituições sociais e culturais, sendo, portanto, a etnopsicopatologia e a psicopatologia social.

Perspectiva compreensiva - possuem a compreensão como eixo fundamental. São a psicopatologia existencialista, a psicopatologia fenomenológica, a psicopatologia psicanalítica, a psicopatologia fundamental e a psicopatologia crítica.

\section{As denominações (identidades?) da psicopatologia fenomenológica}

Com o exame de publicações distintas (Van den Berg, 1966; Cardinalli, 2004; Tatossian, 2006) verificam-se denominações referentes à área que une a psicopatologia à fenomenologia e que podem causar algum tipo de confusão no estudioso de psicopatologia fenomenológica. Essas denominações se referem à fenomenologia psiquiátrica e à Psiquiatria fenomenológica, o que me possibilitaria também perguntar por fenomenologia psicopatológica ou por psicopatologia fenomenológica. Haveria alguma diferença entre essas denominações? Apontariam campos distintos de atuação? Em que situação ou em referência a que usar qual deles, visto que sua elaboração pode se referir a objetos distintos?

No caso de Tatossian (2006), entendendo ser a publicação destinada a apresentar "o quadro da fenomenologia psiquiátrica tal como ela tem sido abordada pelos psiquiatras e não como poderia ou deveria sê-lo a partir" (p. 23) da fenomenologia, o autor parece querer se restringir à Psiquiatria, não por ser a detentora do domínio sobre os entendimentos psicopatológicos, que seguramente não é, mas em razão, inicialmente, das condições pessoais e contextuais da obra: própria formação e prática clínica em psiquiatria, e por ter sido solicitado a escrever a obra citada pelo Congresso de Psiquiatria, justificando assim seu endereço. Ao mesmo tempo, ao longo da obra citada, parece usar indistintamente os termos fenomenologia psiquiátrica e psiquiatria fenomenológica, alternando-os apenas para se referir ao psiquiatra identificado como fenomenólogo ou de orientação fenomenológica. Será, porém, que o uso desses termos pode ser indiscriminado?

A mim me parece que as expressões psiquiatria fenomenológica e psiquiatra fenomenólogo referem-se a uma ciência e a um profissional que fariam uso de uma prática fundamentada na fenomenologia ou em seu método. A Psiquiatria seria a tarefa anterior e principal, a que a fenomenologia serviria como instrumento - ação impossível visto não se configurar a fenomenologia como um sistema aplicável a qualquer que seja a ciência. Ainda se pode dizer, no entanto, de uma psiquiatria que se fundamente na fenomenologia, ou esteja nela implicada, justificando assim o uso do termo. Por sua vez, a denominação de uma fenomenologia psiquiátrica lançaria todo e qualquer estudioso de psicopatologia na restrita possibilidade de estudar a forma como psiquiatras ou praticantes da ação psiquiátrica (médicos, enfermeiros, psicólogos, assistentes sociais e demais profissionais de saúde mental) realizam - concebem e intervêm - a prática na doença mental. Opera-se nova restrição, ainda que mais aberta em relação à primeira, mas possível para aqueles interessados na leitura fenomenológica da Psiquiatria.

Se a Psiquiatria diz respeito ao tratamento das doenças mentais, está subordinada ao amplo espectro em que a psicopatologia se imiscui, colhendo daí subsídios para o estabelecimento da terapêutica. Também, no entanto, realizam os psiquiatras estudos psicopatológicos. Pareceme, portanto, que a melhor adequação é a dicção psicopatologia fenomenológica, por envolver toda e qualquer possibilidade de estudo ou referência à doença mental, inclusive ela mesma, a doença mental, na forma em que pode e participa o próprio doente mental. Estes últimos, então, objetos e objetivos da rigorosa e própria fenomenologia. Dessa maneira, o termo psicopatologia fenomenológica cobrirá amplo espectro de profissionais, cujo objeto último é a doença mental e que por assim o ser e rigorosamente, se valem do método fenomenológico para maior proximidade ao referido objeto.

Quanto à expressão fenomenologia psicopatológica, a entendo como o conjunto de conhecimentos estabelecidos pela fenomenologia ou com origem no seu método, que, não obstante a indissociação que deriva na imbricada relação entre Psiquiatria e fenomenologia, figuram como um já dado e por isso mesmo tornam-se um impeditivo primeiro para o exame de tal ou qual psicopatologia, assim como qualquer outro tipo de conhecimento em curso. Demonstram-se, por conseguinte, meramente como referência de diálogo a posteriori, embora exatamente por isso não se possa minimizar sua importância.

\section{0 que é a psicopatologia fenomenológica}

Tendo, até então, demonstrado a constituição histórica e não natural da psicopatologia, indicado a noção biomédica como vigente, mencionado a diversidade de perspectivas psicopatológicas e ainda afirmado a impossibilidade de adoção da fenomenologia como o conhecimento privilegiado para o estudo da patologia mental, resta-me apontar como se configura uma dita psicopatologia fenomenológica, quais seu escopo e a maneira como se estabelece, ela mesma, para atingir seus propósitos. 
Efetivamente, a psicopatologia fenomenológica será apontada como "a releitura dos fenômenos psiquiátricos privilegiando-se a sincronia entre o desvendamento das estruturas da existência e o movimento engajado pela fenomenologia" (Tatossian, 2006, p. 23). O estudo da psicopatologia fenomenológica implica a "visão" do caráter imediato da experiência do doente mental, transpondo as fronteiras do sensível e realizando uma operação fenomenológica fundamental, sem a interposição de um saber teórico predeterminado de experiência. Significa isto exprimir que, seu objetivo principal implica o contato não mediado com os fenômenos e com o doente mental, da forma como experiencia e vive sua condição, para, então, se lançar num exercício reflexivo (transpor as fronteiras do sensível) de forma que a ação fenomenológica se realize sem a interposição de um conhecimento privilegiado prévio à experiência, mesmo que ele seja a própria fenomenologia.

Reler os fenômenos psiquiátricos implica, com base no ora exposto, em reconsiderar as noções que constituem a psicopatologia tais como os de alucinação e delírio, mas também as próprias ideias dos transtornos mentais já estabelecidos, como depressão e esquizofrenia naquilo que implicam e revelam a estrutura do ser homem postulada pela fenomenologia, como, por exemplo, o ser-no-mundo ou o ser-aí, mais do que na correlação conceitual, mas naquilo que podem contribuir para a explicitação do seu sentido na correlação originária homem-mundo. Evidentemente, outras dimensões da psicopatologia, tais como seus aspectos históricos, teóricos mais amplos e próprias concepções de saúde-doença também estão em foco na psicopatologia fenomenológica, em decorrência do contributo para a revelação desse sentido. Com efeito, a psicopatologia fenomenológica terá, na visão de Tatossian (2006) os seguintes objetivos: a) generalizar a essência revelada sobre um caso único enquanto tal: mostrar que há em cada experiência mais do que o empirismo comum reconhece; b) clarificar (Klären) a experiência, psiquiátrica: torná-la transparente quanto à essência ou a isto que o psiquiatra sabe desde sempre, mas não sabe forçosamente que sabe; c) revelar a estrutura eidética que torna possível os estados psicopatológicos, não como causa, mas como condições de suas possibilidades; e d) suscitar uma unidade entre a pesquisa dos fatos e a busca das essências.

$\mathrm{O}$ exposto remete à ontologia heideggeriana, pois, nessa perspectiva, fenômeno é o que se mostra naquilo que aparece. Tal consideração acentua que o já dado ou o objeto que se mostra traz em si algo de essencial que deve ser buscado, pois já se revela junto com o objeto. Ou seja, o que interessa enquanto estudioso de psicopatologia e psicoterapia, no exame de um caso como tal, é que o mesmo remete ao essencial do humano. Por assim dizer, a singularidade conduz o estudioso à generalidade e a generalidade remete à singularidade. No exame da relação do humano com seu mundo (e posso dizer na relação com qualquer objeto em particular), interessa é o que se revela de humano e não a objetividade de sua condição. É nisto que implica a possibilidade de clarificar ao estudioso de psicopatologia isto que sabe desde sempre, mas não sabe forçosamente que sabe. O sentido da relação estabelecida com as coisas já está sempre aí junto a elas. É nessa circunstância que se opera a relação, mas este sentido é irrefletido e trata-se de evocá-lo para a compreensão da relação. Logo, da condição da psicopatologia e das possibilidades de intervenção para minimização do sofrimento humano.

\section{Referências}

Amatuzzi, M. M. (2009). Psicologia fenomenológica: uma aproximação teórica humanista. Estudos de Psicologia (Campinas), 26(1), 93-100.

Amatuzzi, M. M. (2011). Por uma psicologia humana. Campinas: Alínea.

American Psychiatric Association (1994). Manual Diagnóstico e Estatístico dos Transtornos Mentais - DSM-IV. Porto Alegre: Artmed.

Bucher, R. E. (1989). A psicoterapia pela fala: fundamentos, princípios, questionamentos. São Paulo: EPU.

Canguilhem, G. (2002). O normal e o patológico (M. de T. R. de C. Barrocas \& L. O. F. B. Leite, Trads.). Rio de Janeiro: Forense Universitária (Original publicado em 1966).

Cardinalli, I. E. (2004). Daseinsanalyse e esquizofrenia um estudo na obra de Medard Boss. São Paulo: EDUC: Fapesp.

Chauí, M. (2000). Convite à filosofia (7. ed.). São Paulo: Ática.

Feijoo, A. M. L. C. (2011). A existência para além do sujeito - A crise da subjetividade moderna e suas repercussões para a possibilidade de uma clínica psicológica com fundamentos fenomenológico-existenciais. Rio de Janeiro: Edições IFEN, Via Verita.

Feijoo, A. M. L. C., (2013) O pensamento de Kierkegaard e a clínica fenomenológica. Rio de Janeiro: IFEN.

Forghieri, Y. C. (1993). Psicologia fenomenológica: fundamentos, método e pesquisas. São Paulo: Pioneira.

Foucault, M. (1978). História da loucura na idade clássica. São Paulo: Ed. Perspectiva. (Original publicado em 1961).

Foucault, M. (1984a). Doença mental e psicologia (L. R. Shalders, Trad.). Rio de Janeiro: Tempo Brasileiro. (Original publicado em 1962).

Foucault, M. (1984b). Eu, Pierre Rivière, que degolei minha mãe, minha irmã e meu irmão - Um caso de parricídio do século XIX, apresentado por Michel Foucault (D. L. de Almeida, Trad.). Rio de Janeiro: Graal. (Original publicado em 1973).

Giorgi, A. (2009). The descriptive phenomenological method in psychology: A modified Husserlian approach. Pittsburg, PA: Duquesne University. 
Goto, T. A. (2008). Introdução à psicologia fenomenológica a nova psicologia de Edmund Husserl. São Paulo: Paulus.

Heidegger, M. (1993). Ser e tempo (2 Vols.) (M. de S. Cavalcante, Trad.). Petrópolis: Vozes (Original publicado em 1927).

Heidegger, M. (2006). Qué significa pensar? (R. Gabás, Trad.) Madrid: Editorial Trotta. (Original publicado em 1954).

Heidegger, M. (2006). Os conceitos fundamentais da metafísica: Mundo, finitude, solidão (M. A. Casanova, Trad.). Rio de Janeiro: Forense Universitária. (Original publicado em 1930).

Heidegger, M. (2008). Marcas do caminho (E. P. Giachini \& E. Stein, Trads.) (M. A. Casanova, Rev.). Petrópolis: Vozes (Original publicado em 1967).

Heidegger, M. (2009). Sobre a questão do pensamento (E. Stein, Trad.). Petrópolis: Vozes (Original publicado em 1969).

Heidegger, M. (2010). Meditação (M. A. Casanova, Trad.). Petrópolis: Vozes (Original publicado em 1930).

Holanda, A. F. (2002). O resgate da fenomenologia de Husserl e a pesquisa em psicologia. Tese de Doutorado em Psicologia, Pontifícia Universidade Católica de Campinas, Campinas.

Holanda, A. F. (2011). Gênese e histórico da Psicopatologia. Em V. A. Angerami (Org.), Psicoterapia e brasilidade (p. 115-155). São Paulo: Cortez.

Inwood, M. (2002). Dicionário Heidegger. Rio de Janeiro: Jorge Zahar Editora.

Ionescu, S. (1995). Quatorze abordagens de psicopatologia. Porto Alegre: Artes Médicas.

Karwowski, S. L. (2005). Gestalt-terapia e fenomenologia. Campinas: Ed. Livro Pleno.

Martins, F. (1999). O que é phatos. Revista Latinoamericana de Psicopatologia Fundamental, 2(4), 62-79.

Moreira, V., \& Sloan, T. (2002). Personalidade ideologia e psicopatologia crítica. São Paulo: Escuta.

Pattison, G. (2001). The Later Heidegger - Routledge Philosophy GuideBook to. Londres: Taylor \& Francis e-Library.

Ramos, D. G. (1994). A psique do corpo - uma compreensão simbólica da doença. São Paulo: Summus.

Sartre, J. P. (2007). O ser e o nada - Ensaio de ontologia fenomenológica (15. ed.). (P. Perdigão, Trad.). Petrópolis: Vozes.

Schultz, D., \& Schultz, S. E. (1994). História da psicologia moderna. São Paulo: Cultrix.

Stein, E. (1976). Melancolia: ensaios sobre a finitude no pensamento ocidental. Porto Alegre: Editora Movimento.

Stein, E. (2006). Pensar é pensar a diferença: filosofia e conhecimento empírico. Ijuí: Editora Unijuí.

Tatossian, A. (2006). Fenomenologia das psicoses. São Paulo: Escuta.
Van den Berg, J. H. (1966). O paciente psiquiátrico - esboço de psicopatologia fenomenológica. São Paulo: Editora Mestre Jou.

Vaz, H. C. de L. (1992). Antropologia filosófica. São Paulo: Loyola.

Silverio Lucio Karwowski - Psicólogo, Especialista em Gestalt-terapia pelo Instituto Sedes Sapientiae de São Paulo, Mestre em Psicologia Clínica pela Pontifícia Universidade Católica de Campinas, Professor do Curso de Formação em Gestalt-terapia do IGC - Instituto Gestalt do Ceará, Editor Responsável do Boletim de Gestalt-terapia e Professor do Centro Universitário Estácio do Ceará (Fortaleza/CE) e da Universidade de Fortaleza - UNIFOR. Endereço Institucional: R. João Regino, 474 Parque Manibura, Fortaleza/CE. CEP: 60.821-780.

E-mail: silukarw@gmail.com

Recebido em 04.02.2014

Primeira Decisão Editorial em 29.04.2014 Segunda Decisão Editorial em 09.07.2014 Aceito em 01.12.2014 